\title{
A Collagen Defect in Homocystinuria
}

\author{
Andrew H. Kang and Robert L. Trelstad \\ From the Developmental Biology Laboratory, Departments of Medicine and \\ Pathology, Massachusetts General Hospital and Harvard Medical School, \\ Boston, Massachusetts 02114, and the Departments of Medicine and \\ Biochemistry, Veterans Administration Hospital, and The University of \\ Tennessee Medical School, Memphis, Tennessee 38104
}

A B S TRACT The biochemical mechanism accounting for the connective tissue abnormalities in homocystinuria was explored by examining the effects of various amino acids known to accumulate in the plasma of patients with this disease on cross-link formation in collagen. Neutral salt solutions of purified, rat skin collagen, rich in cross-link precursor aldehydes, were polymerized to native type fibrils by incubating at $37^{\circ} \mathrm{C}$ in the presence of homocysteine, homocystine, or methionine. After the polymerization was completed, each sample was examined for the formation of covalent intermolecular cross-links, assessed indirectly by solubility tests and directly by measuring the cross-link compounds after reduction with tritiated sodium borohydride and hydrolysis.

Collagen solutions containing homocysteine $(0.01 \mathrm{M}-$ $0.1 \mathrm{M}$ ) failed to form insoluble fibrils. Furthermore, much less of the reducible cross-links, $\Delta^{6,7}$ dehydrohydroxylysinonorleucine, $\Delta^{6,7}$ dehydrohydroxylysinohydroxynorleucine, and histidino-dehydrohydroxymerodesmosine were formed in the preparations containing homocysteine as compared with the control and the samples containing methionine or homocystine. The content of the precursor aldehydes, $\alpha$-aminoadipic- $\delta$-semialdehyde (allysine) and the aldol condensation product, was also markedly diminished in tropocollagen incubated with homocysteine. It is concluded that homocysteine interferes with the formation of intermolecular

A portion of this work was presented at the joint meeting of the American Society for Clinical Investigation, Atlantic City, N. J. April 1972. This is publication no. 610 of Robert W. Lovett Group for Study of Diseases Causing Deformities.

Dr. Kang is a Medical Investigator of Veterans Administration.

Dr. Trelstad is a Fellow of the Helen Hay Whitney Foundation.

Received for publication 5 February 1973 and in revised furm 15 May 1973.

The Journal of Clinical Investigation Volume 52 October 1973.2571-2578 cross-links that help stabilize the collagen macromolecular network via its reversible binding to the aldehydic functional groups.

Analysis of the collagen cross-links in skin biopsy samples obtained from three patients with documented homocystinuria showed that the cross-links were significantly decreased as compared with the age-matched controls, supporting the tentative conclusions reached from the in vitro model studies. In addition, the solubility of dermal collagen in non-denaturing solvents was significantly increased in the two patients examined, reflecting a functional defect in collagen cross-linking. Although the concentration of homocysteine used in this study to demonstrate these effects in vitro is clearly higher than that which is observed in homocystinuric's plasma, the data do suggest a possible pathogenetic mechanism of connective tissue defect in homocystinuria.

\section{INTRODUCTION}

Homocystinuria is a metabolic disease inherited as an autosomal recessive, characterized biochemically by homocysteinemia, homocystinemia, hypermethioninemia, and homocystinuria, the last a variety of "overflow" amino aciduria due to the accumulation of the amino acid in the blood (1). The basic defect has been shown to be the deficient activity of the enzyme, cystathionine synthetase in these patients (2), which catalyzes the synthesis of cystathionine from homocysteine and serine in the methionine pathway. Deficient activity of the enzyme then results in the accumulation of homocysteine and other metabolites including methionine. Homocystine that the affected individual excretes is presumably derived from oxidation of homocysteine.

The disease is characterized clinically by widespread deformities and malfunctions of connective tissue including joint laxity, kyphoscoliosis, pigeon breast, genu valgum, severe osteoporosis, ectopia lentis, and vascular 
disease in which dilatation and thrombosis of mediumsized arteries and veins occur frequently. Despite the delineation of the enzymatic defect responsible for the altered amino acid metabolism the pathogenetic mechanisms by which these metabolic defects lead to the connective tissue malformations are poorly understood. However, in view of similarities in some of the clinical manifestations of connective tissue diseases in these patients to experimental osteolathyrism (3), it was suggested by McKusick (1) that a collagen cross-linking defect might be similar to that shown in lathyrism $(4,5)$. The structural similarity of homocysteine to Dpenicillamine led to the speculation that, like the latter, homocysteine might also interfere with the collagen (and elastin) cross-linking by binding to the precursor aldehydes $(1,6-8)$. Good evidence is available for such a mechanism of action by D-penicillamine (9-11). However, no experimental evidence for such a mechanism of action by homocysteine has been obtained to our knowledge. Harris and Sjoerdsma (6) did report that in two out of four patients with homocystinuria, solubility of dermal collagen was increased over control patients, suggesting a defect in collagen cross-linking. They did not, however, measure the cross-link content directly.

Evidence to date indicates that collagen cross-linking involves oxidative deamination of certain lysyl residues to form allysine ( $\alpha$-aminoadipic- $\delta$-semialdehyde) that then reacts via Schiff base formation with an $\epsilon$-amino group of a lysyl or hydroxylysyl residue located on an adjacent molecule to form the reducible intermolecular cross-links, $\Delta^{\theta, 7}$ dehydrolysinonorleucine or $\Delta^{6,7}$ dehydrohydroxylysinonorleucine (12-16). In a separate pathway, two residues of the aldehyde, allysine, may condense in an aldol condensation to form the "intra"molecular cross-link (17-21). The aldol product, which contains a reactive aldehyde, further participates in the formation of a higher complex cross-link, tentatively designated "post-histidine compound" $(16,22)$ and recently identified as histidino-hydroxymerodesmosine $(23,24)$. In addition, another Schiff base $\Delta^{8,7}$ dehydrohydroxylysinohydroxynorleucine has been identified as a cross-link in certain collagens including human (25), but its biosynthetic origin has not yet been established. In all of these reactions, the integrity of the aldehyde appears essential, since its reduction by borohydride results in complete loss of the ability to form the crosslinks by the reduced collagen (16). Similarly, binding of the functional group by any agent such as D-penicillamine also interferes with cross-linking (10).

In the present paper, we report the results of our studies on the effect of homocysteine and other related metabolites on the collagen cross-linking and the results of examination of the dermal collagen of patients with homocystinuria for direct evidence of cross-link impairment and alteration in solubility.

\section{METHODS}

Preparation of collagen. Acetic acid-extracted collagen, rich in aldehydic precursors of collagen cross-links (17, $18,21)$, was prepared from the dorsal skin of normal, young (150-200 g) male Sprague-Dawley rats (CD strain, Charles River Breeding Laboratories, Wilmington, Mass.). Lathyritic, cold neutral salt-extracted collagen was obtained from another group of animals that had been fed a Purina rat chow containing $2 \mathrm{~g} / \mathrm{kg}$ of $\beta$-aminopropionitrile fumarate (Aldrich Chemical Co., Inc., Milwaukee, Wisc.) for 2 wk. The skins were cleaned, ground in a mechanical meat grinder in the cold, washed with cold distilled water, and extracted with $0.05 \mathrm{M}$ Tris, $\mathrm{pH} 7.4$ containing $1 \mathrm{M}$ $\mathrm{NaCl}$, overnight at $4^{\circ}$. The residue from the normal animals was then extracted further with $0.5 \mathrm{M}$ acetic acid. The collagen present in the $1 \mathrm{M} \mathrm{NaCl}$ extract of the lathyritic tissue and the $0.5 \mathrm{M}$ acetic acid extract of the normal tissue was purified by the method described elsewhere (21). Purified collagen was stored in a lyophilized state in a desiccator over $\mathrm{P}_{2} \mathrm{O}_{5}$ in the cold.

In vitro fibril formation. Native-type fibrils were formed from the soluble collagen by a modification (16) of the method described by Gross and Kirk (26). Briefly, purified soluble collagen was solubilized in cold $0.1 \mathrm{M}$ acetic acid $(1 \mathrm{mg} / \mathrm{ml})$ and dialyzed vs. $0.05 \mathrm{M}$ Tris, $\mathrm{pH} 7.4$ containing $0.16 \mathrm{M} \mathrm{NaCl}$ in the cold. Any insoluble material was removed by centrifugation in a Spinco ultracentrifuge (Spinco Div., Beckman Instruments, Palo Alto, Calif.) at $105,000 \mathrm{~g}$ for $2 \mathrm{~h}$. To aliquots of the neutral saline solution of collagen, varying amounts of the amino acids, homocysteine (free base), homocystine, or methionine were added. In all experiments, homocysteine was freshly prepared from homocysteinethiolactone immediately prior to use by $2 \mathrm{~N} \mathrm{NaOH}$ treatment (27). The reaction vessels were immediately sealed under nitrogen and incubated in a water bath maintained at $37^{\circ}$ to form the native-type fibrils (26). The course of fibril formation was followed by measuring the opacity in a Klett colorimeter (Klett Manufacturing Co., Inc., New York). The gelation usually reached a maximum within hours. In some experiments the gels were cooled to $4^{\circ}$ at the end of a $24 \mathrm{~h}$ incubation period. The opacity of the solution was used as an index of the degree of collagen aggregation.

Reduction with tritiated sodium borohydride. In order to assay the cross-link content and other related compounds, collagen samples were reduced with calibrated $\mathrm{NaB}^{3} \mathrm{H}_{4}$ (200 $\mathrm{mCi} / \mathrm{mM}$, New England Nuclear Corp., Boston, Mass.) using 100-fold molar excess as previously described $(16,28)$. The reaction was carried out for $30 \mathrm{~min}$ at room temperature. Excess reagent was destroyed by adjusting the $\mathrm{pH}$ of the reaction mixture to 4.0 with $1 \mathrm{M}$ acetic acid, and the salts were removed by exhaustive dialysis against $0.1 \mathrm{M}$ acetic acid.

Solubility of thermally precipitated collagen reduced with $\mathrm{NaB}^{3} \mathrm{H}_{4}$. The collagen gels reduced with $\mathrm{NaB}^{3} \mathrm{H}_{4}$ and dialyzed against $0.1 \mathrm{M}$ acetic acid as described above were centrifuged at $40,000 \mathrm{~g}$ for $1 \mathrm{~h}$ at $4^{\circ}$, and the precipitate and the supernates were analyzed for hydroxyproline on an amino acid analyzer.

Clinical materials. 6-mm punch biopsies were obtained from two patients (K. S. and K. J.) with documented homocystinuria through the cooperation of Dr. Ellen S. Kang of the Children's Hospital Medical Center, and from 
another patient (T. K.) by Dr. Richard Erbe of Massachusetts General Hospital, Harvard Medical School, Boston, Mass. 10 age-matched control samples were obtained from normal volunteers and surgical patients at the Children's Hospital Medical Center, Massachusetts General Hospital or the Veterans Administration Hospital, Memphis, Tennessee.

Samples of dermis were frozen in liquid nitrogen and pulverized into powder using a stainless steel cup and pestle that had been immersed in liquid nitrogen. After thawing, the samples were washed with cold distilled water and suspended in $0.05 \mathrm{M}$ Tris, $\mathrm{pH} 7.4$ containing $0.16 \mathrm{M}$ $\mathrm{NaCl}$, and reduced with $\mathrm{NaB}^{3} \mathrm{H}_{4}$ as described above.

Aliquots of the powderized samples from two of the patients (K. S. and K. J.) were also examined for solubility of collagen in nondenaturing solvents. Each sample was extracted in the cold with 50 vol (volume to wet weight ratio) of $1.0 \mathrm{M} \mathrm{NaCl}, 0.05 \mathrm{M}$ Tris, $\mathrm{pH} 7.4$ for 3 days with two changes and $0.5 \mathrm{M}$ acetic acid for 6 days with two changes. The insoluble residue was separated from the supernate by centrifugation at $40,000 \mathrm{~g}$ at $4^{\circ}$ for $30 \mathrm{~min}$. The amount of extracted collagen and insoluble collagen was determined by hydroxyproline assay (29). Two control samples were similarly studied.

Amino acid analysis and scintillation spectrometry. Each sample was equally divided and hydrolyzed separately in constant boiling $\mathrm{HCl}$ in tubes sealed under an atmosphere of nitrogen and in $2 \mathrm{~N} \mathrm{NaOH}$ for $24 \mathrm{~h}$ at $108^{\circ}$. Analyses were performed on a Beckman 121 or Jeolco automatic amino acid analyzer equipped with a stream-split device as described previously (16). The acid hydrolyzates, used for detection and quantitation of the reduced intermolecular cross-links (hydroxylysinonorleucine, hydroxylysinohydroxynorleucine, and histidino-hydroxymerodesmosine), were analyzed using a modification of the buffer system described by Hamilton $(30)$. The alkaline hydrolyzates, used for quantitation of the precursor aldehyde (hydroxynorleucine) and the intramolecular cross-link (aldol condensation product) were analyzed using the gradient of Burns, Curtis, and Kaeser (31). A portion of the effluent was continuously monitored for ninhydrin reactivity, and the remaining portion was collected in fractions of $1 \mathrm{ml}$. Radioactivity of the individual fractions was determined in a liquid scintillation counter using Aquasol (New England Nuclear).

Electron microscopy. The ultrastructure of thermally precipitated collagen samples was monitored by electron microscopy. Small aliquots of each sample containing fibrils were applied to grids coated with a colloidion film, stained with $2 \%$ uranyl acetate for $15 \mathrm{~min}$ and examined in an RCA EMU $3 \mathrm{G}$ electron microscope. In addition, aliquots of each sample were fixed in glutaraldehyde, embedded in Epon (Fisher Scientific Co., Pittsburgh, Pa.) and examined after sectioning in the electron microscope.

\section{RESULTS}

Neutral salt solutions $(0.05 \mathrm{M}$ Tris $-0.16 \mathrm{M} \mathrm{NaCl}, \mathrm{pH}$ 7.4) of collagen were incubated at $37^{\circ}$ in the presence of varying concentrations of homocysteine, homocystine, and methionine along with a control and a solution of lathyritic collagen to compare their capacity to form insoluble native-type fibril aggregates. The results are shown in Fig. 1. Collagen solutions containing various amounts of homocysteine or methionine up to the concentration of $0.1 \mathrm{M}$, and $0.05 \mathrm{M}$ in the case of homo-

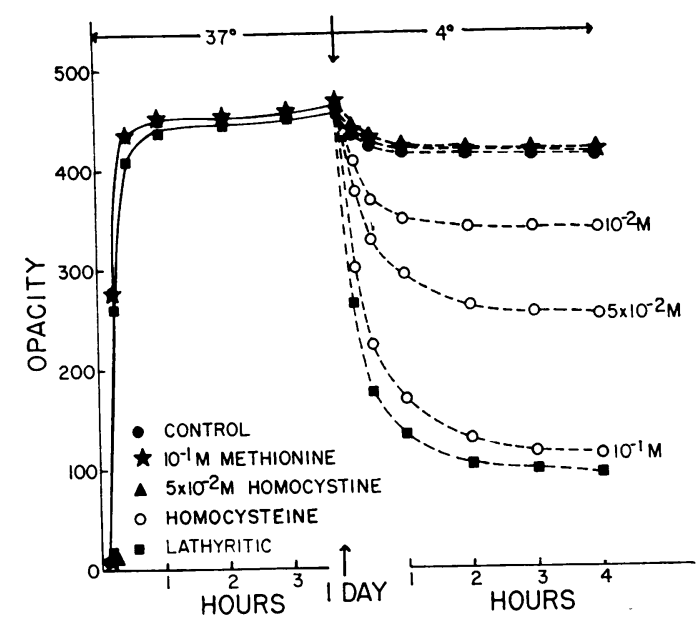

FIGURE 1 Thermal gelation of purified lathyritic and acidextracted normal collagen and the effects of various amino acids. Collagen solutions $(1 \mathrm{mg} / \mathrm{ml})$ in $0.05 \mathrm{M}$ Tris- 0.16 $\mathrm{M} \mathrm{NaCl}, \mathrm{pH} 7.4$ were warmed to $37^{\circ}$ and the rate of thermal aggregation was measured by the change in opacity in a Klett colorimeter. Test solutions contained various concentrations of homocysteine $\left(10^{-1} \mathrm{M}, 5 \times 10^{-2} \mathrm{M}\right.$, or $\left.10^{-2} \mathrm{M}\right)$, methionine $\left(10^{-1} \mathrm{M}\right)$ or homocystine $\left(5 \times 10^{-2} \mathrm{M}\right)$. After incubation at $37^{\circ}$ for $24 \mathrm{~h}$, the tubes were cooled to $4^{\circ}$ in a water bath and the changes in opacity were recorded.

cystine, gel rapidly at $37^{\circ}$ and reach a maximum opacity within $1 \mathrm{~h}$ of incubation as does a solution of lathyritic collagen. Concentrations of homocystine greater than $0.05 \mathrm{M}$ were not tested because of its insolubility. There are no significant differences in the maximal opacity attained by the various samples. After incubation at $37^{\circ}$ for $24 \mathrm{~h}$, each sample was examined for reversibility of fibril formation upon cooling to $4^{\circ}$ as described by Gross (32). The fibrils from lathyritic collagen, containing low content of the cross-link precursor aldehydes, are rapidly redissolved under these conditions reflecting its inability to form intermolecular crosslinks (5). However, the acid-extracted normal collagen does not show significant redissolution, indicating formation of stable intermolecular cross-links during the incubation period. The presence of $0.1 \mathrm{M}$ homocysteine in the normal collagen solution almost completely prevents the insolubilization of the fibrils, suggesting interference by the amino acid with crosslink formation. At lower concentrations, partial inhibition is noted. That this inhibition of insolubilization is specific for homocysteine is shown by the fact that both homocystine and methionine have no effect.

Since it is well established that the in vitro collagen cross-link formation requires the stereospecificity of the native-type fibrils, it was important to determine whether homocysteine interfered with the native-type fibril aggregation, as it had been previously shown that cross-linking failed to occur in any aggregates other 
TABLE I

Solubility of Collagen Fibrils Thermally Polymerized in the Presence of Homocysteine, Homocystine, or Methionine and Subsequently Reduced with $\mathrm{NaB}^{3} \mathrm{H}_{4}$

\begin{tabular}{lc}
\hline \multicolumn{1}{c}{ Collagen sample } & $\begin{array}{c}\text { Collagen soluble } \\
\text { in } 0.1 \mathrm{M} \\
\text { acetic acid }\end{array}$ \\
\hline & $\%$ \\
Acetic acid-extracted normal collagen & 12 \\
Lathyritic collagen & 89 \\
Acetic acid-extracted normal collagen & \\
+0.1 M homocysteine & 85 \\
+0.05 M homocysteine & 40 \\
+0.01 M homocysteine & 19 \\
+0.05 M homocystine & 14 \\
$+0.1 \mathrm{M}$ methionine & 13 \\
\hline
\end{tabular}

than the native-type $640 \AA$ banded fibrils (11). An aliquot of the collagen aggregated in the presence of $0.1 \mathrm{M}$ homocysteine, therefore, was examined by electron microscopy. All of the fibrils display the typical band pattern with $640 \AA$ periodicity as do the control samples. Thus, the effect of homocysteine was not mediated through nonspecific interference with native-type fibril formation.

These observations were further substantiated by the quantitative analysis of the various cross-link compounds and solubility of the thermally precipitated gels after $24 \mathrm{~h}$ incubation and reduction with $\mathrm{NaB}^{3} \mathrm{H}_{4}$. Reduction with $\mathrm{NaB}^{3} \mathrm{H}_{4}$ introduces one atom per mole of non-exchangeable tritium into the aldehydes of allysine and the aldol condensation product and into the Schiff base forms of hydroxylysinonorleucine, hydroxylysinohydroxynorleucine, and histidino-hydroxymerodesmosine $(16,22-24)$ thus allowing quantitation of these compounds by radioactivity assay and at the same time stabilizing them to subsequent analytic procedure. The solubility data, summarized in Table I, clearly show that homocysteine prevents insolubilization of the collagen fibrils even after subsequent borohydride reduction, implying that the stable cross-links are not formed. Lathyritic collagen, lacking the necessary functional (aldehyde) groups, is unable to form insoluble fibrils. These results are confirmed by the direct assay of the cross-link compounds as presented in Table II. The amounts of the intermolecular cross-links generated, hydroxylysinonorleucine, hydroxylysinohydroxynorleucine, and histidino-hydroxymerodesmosine are markedly diminished by $0.1 \mathrm{M}$ homocysteine.

In order to investigate the mechanism by which homocysteine prevents the formation of the intermolecular cross-links, the effect of the amino acid on the integrity of the precursor aldehyde functional groups on the tropocollagen was investigated. The hypothesis to be tested was whether the amino acid might interact with the aldehydes in a manner analogous to that described for D-penicillamine (10) and as has been suggested for homocysteine $(1,7,8)$. Acid-extracted normal collagen, solubilized in $0.05 \mathrm{M}$ Tris, $\mathrm{pH} 7.4$, containing $0.16 \mathrm{M} \mathrm{NaCl}$ was incubated with homocysteine at room temperature along with appropriate control samples and was directly reduced with $\mathrm{NaB}^{3} \mathrm{H}_{4}$. The reduced samples were then analyzed for the content of $\epsilon$-hydroxynorleucine (reduction product of allysine) and the reduced aldol condensate after hydrolysis in 2 $\mathrm{N} \mathrm{NaOH}$. The results are presented in Table III. These data indicate that homocysteine in concentrations of $0.01-0.1 \mathrm{M}$ interacts in some manner with the aldehyde groups of allysine and the aldol residues. Apparently, this interaction is reversible, since the collagen samples incubated with $0.1 \mathrm{M}$ homocysteine at $37^{\circ}$ for $24 \mathrm{~h}$ are capable of forming insoluble gels after exhaustive di-

TABLE II

Content of the Cross-links Generated in the Collagen Fibrils during Incubation with Homocysteine, Homocystine, and Methionine*

\begin{tabular}{lccc}
\hline \multicolumn{1}{c}{ Collagen sample } & $\begin{array}{c}\text { Hydroxylysino- } \\
\text { hydroxynorleucine }\end{array}$ & $\begin{array}{c}\text { Hydroxylysino- } \\
\text { norleucine }\end{array}$ & $\begin{array}{c}\text { Histidino- } \\
\text { hydroxymerodesmosine }\end{array}$ \\
\hline Acetic acid-extracted normal collagen & $20 \times 10^{4}$ & $55 \times 10^{4}$ & $80 \times 10^{4}$ \\
Lathyritic collagen & $3 \times 10^{4}$ & $9 \times 10^{4}$ & $12 \times 10^{4}$ \\
Acetic acid-extracted normal collagen & $1 \times 10^{4}$ & $12 \times 10^{4}$ & $10 \times 10^{4}$ \\
+0.1 M homocysteine & $10 \times 10^{4}$ & $27 \times 10^{4}$ & $42 \times 10^{4}$ \\
+0.05 M homocysteine & $15 \times 10^{4}$ & $40 \times 10^{4}$ & $69 \times 10^{4}$ \\
+0.01 M homocysteine & $19 \times 10^{4}$ & $57 \times 10^{4}$ & $82 \times 10^{4}$ \\
+0.05 M homocystine & $22 \times 10^{4}$ & $52 \times 10^{4}$ & $78 \times 10^{4}$ \\
+0.1 M methionine & &
\end{tabular}

* Measured after reduction with $\mathrm{NaB}^{3} \mathrm{H}_{4}$ and expressed as total cpm per $10 \mathrm{mg}$ of collagen. The amounts of collagen were calculated from amino acid analysis assuming 92 residues of hydroxyproline per 1,000 residues of amino acids. The data obtained from $6 \mathrm{~N} \mathrm{HCl}$ hydrolyzates of the $\mathrm{NaB}^{3} \mathrm{H}_{4}$ reduced samples. 
TABLE III

Effecls of Homocysteine, Homocystine, and Methionine on the Cross-link Precursor Aldehydes*

\begin{tabular}{ccc}
\hline Collagen samples & e-hydroxynorleucine & Reduced aldol \\
\hline $\begin{array}{c}\text { Acid-extracted normal } \\
\text { collagen }\end{array}$ & $62 \times 10^{4}$ & $70 \times 10^{4}$ \\
Lathyritic collagen & $9 \times 10^{4}$ & $10 \times 10^{4}$ \\
Acid-extracted normal & & \\
collagen & $2 \times 10^{4}$ & $2 \times 10^{4}$ \\
$+0.1 \mathrm{M}$ homocysteine & $30 \times 10^{4}$ & $32 \times 10^{4}$ \\
$+0.05 \mathrm{M}$ homocysteine & $51 \times 10^{4}$ & $59 \times 10^{4}$ \\
$+0.01 \mathrm{M}$ homocysteine & $65 \times 10^{4}$ & $72 \times 10^{4}$ \\
$+0.05 \mathrm{M}$ homocystine & $59 \times 10^{4}$ & $09 \times 10^{4}$ \\
$+0.1 \mathrm{M}$ methionine & & \\
\hline
\end{tabular}

* Data obtained from $2 \mathrm{~N} \mathrm{NaOH}$ hydrolyzates of the $\mathrm{NaB}^{3} \mathrm{H}_{4}$ reduced collagen. Expressed as total $\mathrm{cpm}$ per $10 \mathrm{mg}$ of protein. The amounts of protein were calculated from amino acid analysis assuming 28 residues of lysine per 1,000 total residues, since hydroxyproline is partly destroyed during hydrolysis.

alysis against $0.05 \mathrm{M}$ Tris- $0.16 \mathrm{M} \mathrm{NaCl}, \mathrm{pH} \mathrm{7.4 \text {,as }}$ shown in Fig. 2.

In view of these in vitro experiments indicating "lathyrogenic" effects of homocysteine on collagen, we considered the possibility that similar effects might be observed in the tissues of patients with homocystinuria. Accordingly, dermal collagen of skin biopsies from patients with homocystinuria and age-matched controls was examined for the content of $\epsilon$-hydroxynorleucine and the cross-link compounds after reduction with $\mathrm{NaB}^{3} \mathrm{H}_{4}$. The results are tabulated in Table IV. The content of both the precursor aldehyde, $\epsilon$-hydroxynorleucine, and the cross-link compounds, hydroxylysinonorleucine, hydroxylysinohydroxynorleucine, and histidino-hydroxymerodesmosine are significantly decreased. These findings are consistent with the above in vitro data suggesting collagen aldehyde-homocysteine interaction. Decreased content of these compounds are also observed in the sodium borohydride-reduced dermal tissues of human patients who had been treated with D-penicillamine (Kang, A. H., unpublished data).

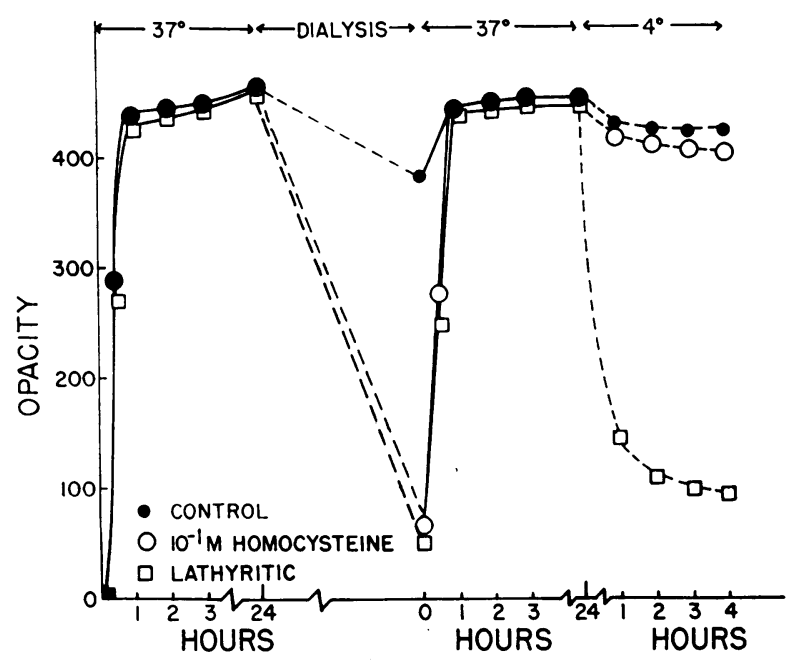

FIGURE 2 Reversibility of homocysteine effect on thermal aggregation of collagen by dialysis. After $24 \mathrm{~h}$ incubation at $37^{\circ}$, the collagen solution containing $10^{-1} \mathrm{M}$ homocysteine was dialyzed vs. the same buffer for $48 \mathrm{~h}$ at $4^{\circ}$ with several changes. Lathyritic and control samples were kept at $4^{\circ}$ without dialysis. Note that following dialysis, the test solution becomes insoluble upon incubation at $37^{\circ}$.

In addition, the solubility of dermal collagen in nondenaturing solvents ( $1 \mathrm{M} \mathrm{NaCl}$ and $0.5 \mathrm{M}$ acetic acid) of two patients examined (K. S. and K. J.) is significantly increased as compared with the controls (Table $\mathrm{V})$. These results are consistent with the increased solubility of dermal collagen and increased $\alpha: \beta$ ratio in homocystinuria previously reported by Harris and Sjoerdsma (6). It is of interest to note that the two younger patients (K. S. and K. J.) who both show greater diminution in the cross-link content (Table IV) are vitamin $B_{8}$ unresponsive patients. Patient T. K., who shows a lesser decrease, is a vitamin $\mathrm{B}_{\boldsymbol{\theta}}$ responsive patient and was on therapy at the time the biopsy was obtained. However, the small number of samples does not allow any definitive conclusion in this regard.

TABLE IV

Content of $\epsilon$-Hydroxynorleucine and Cross-link Compounds of Dermal Collagen in Homocystinuria*

\begin{tabular}{lccccc}
\hline Patient & Age & $\begin{array}{c}\text { e-Hydroxy- } \\
\text { norleucine }\end{array}$ & $\begin{array}{c}\text { Hydroxylysino- } \\
\text { hydroxynorleucine }\end{array}$ & $\begin{array}{c}\text { Hydroxylysino- } \\
\text { norleucine }\end{array}$ & $\begin{array}{c}\text { Histidino- } \\
\text { hydroxymerodesmosine }\end{array}$ \\
\hline K. S. & 12 & $1.8 \times 10^{3}$ & $3.0 \times 10^{3}$ & $12.3 \times 10^{3}$ & $10.9 \times 10^{3}$ \\
K. J. & 9 & $1.0 \times 10^{3}$ & $2.0 \times 10^{3}$ & $8.9 \times 10^{3}$ & $7.4 \times 10^{3}$ \\
T. K. & 27 & $4.0 \times 10^{3}$ & $7.5 \times 10^{3}$ & $21.3 \times 10^{3}$ & $18.0 \times 10^{3}$ \\
Control & $9-12$ & $5.5 \times 10^{3}$ & $20.0 \times 10^{3}$ & $26.9 \times 10^{3}$ & $30.2 \times 10^{3}$ \\
Control & $20-30$ & $9.0 \times 10^{3}$ & $19.1 \times 10^{3}$ & $32.0 \times 10^{3}$ & $39.4 \times 10^{3}$ \\
\hline
\end{tabular}

* Measured after reduction with $\mathrm{NaB}^{3} \mathrm{H}_{4}$ and expressed as cpm per micromole of hydroxyproline. The data for hydroxylysinohydroxynorleucine, hydroxylysinonorleucine, and histidino-hydroxymerodesmosine were obtained from $6 \mathrm{~N} \mathrm{HCl}$ hydrolyzates and $\epsilon$-hydroxynorleucine from $2 \mathrm{~N} \mathrm{NaOH}$ hydrolyzates. 
TABLE V

Solubility of dermal collagen* in Two Subjects with Homocystinuria

\begin{tabular}{lrc}
\hline \multicolumn{1}{c}{ Patient } & Age & $\begin{array}{c}\% \\
\text { Extracted }\end{array}$ \\
\hline K. S. & 12 & 7.8 \\
K. J. & 9 & 10.1 \\
Controls (2) & 11 & $2.4,2.9$ \\
\hline
\end{tabular}

* Combined $1.0 \mathrm{M} \mathrm{NaCl}$ and $0.5 \mathrm{M}$ acetic acid extracts.

\section{DISCUSSION}

The unusual mechanical stability of collagen fibrils and the collagenous tissues is largely dependent on the formation of covalent intermolecular cross-links. The critical importance of these cross-links is best exemplified by the dramatic functional failure of connective tissues observed in experimental lathyrism $(3,4)$, a state that can be induced by administration of lathyrogens such as $\beta$-aminopropionitrile and in which the affected animals display a variety of connective tissue $a b$ normalities including marked skeletal deformities such as kyphoscoliosis and curvature of long bones and vascular abnormalities among others. Recent investigations from several laboratories (33-35) have established that $\beta$-aminopropionitrile acts by inhibiting the lysyl oxidase involved in the biosynthesis of allysine (and presumably hydroxylysine-derived aldehyde as well), the cardinal initial reaction in a series of steps leading to cross-link formation. Thus, lathyritic collagen is deficient in the cross-link precursor, allysine, and is unable to form stable intermolecular cross-links.

Recent studies have revealed another class of lathyrogenic compounds, best understood in the case of D-penicillamine, which exerts its effect at a different step in the biosynthesis of collagen cross-links $(9,10)$. D-penicillamine does not interfere with the allysine formation but rather acts by binding to the aldehydic functional groups, preventing further reaction to form the cross-links (9, 10).

The remarkable similarities in some of the clinical manifestations of lathyrism to those observed in homocystinuria and the structural similarity of D-penicillamine to homocysteine have led some authors $(1,6-8)$ to suggest the possibility that homocysteine might produce defects in collagen cross-linking in homocystinurics in a manner analogous to D-penicillamine and stimulated us to undertake the present investigation. We have shown that only homocysteine but not homocystine and methionine, also increased in the plasma of the patients, interferes with stable intermolecular cross-link formation by interaction with aldehydic groups; they are thus prevented from participating in the cross-linking reactions as measured by the in vitro gelation method, by the reversible solubility of the "aged" and borohydride reduced gels, and by the direct assay of the precursor aldehydes and the cross-links generated during in vitro incubation. Although the concentrations of homocysteine used in our in vitro studies, $0.01 \mathrm{M}-0.1 \mathrm{M}$, are clearly higher than the levels observed in the patient's plasma, the increased solubility of collagen in non-denaturing solvents and the decreased content of the collagen crosslink precursor aldehyde and the cross-link compounds observed in the skin biopsies from the patients suggest strongly that our interpretation for the mechanism of reaction is correct.

The higher concentration of homocysteine required in our in vitro experiments should not necessarily invalidate the proposed mechanism, since a similar disparity between in vitro and in vivo studies with D-penicillamine also has been observed. It has been reported that a D-penicillamine concentration of $0.4 \mathrm{mg} / \mathrm{ml}$ is required for any discernible effect on allysine of elastin in vitro (36). In our laboratory, using an identical in vitro system as described in this paper, the minimum concentration of $\mathrm{D}$-penicillamine required for a definitely discernible effect on allysine of collagen is $0.5 \mathrm{mg} / \mathrm{ml}$ (Kang, A. H., and C. Franzblau, unpublished data). On the other hand, human patients treated with D-penicillamine at a dose of $2 \mathrm{~g} /$ day have been reported to show an increased solubility and a decreased content of $\boldsymbol{\beta}$-components of collagen (37). Although the plasma concentration of D-penicillamine in these patients were not reported, it would seem reasonable to suggest that the plasma concentration must be considerably lower than $0.5 \mathrm{mg} / \mathrm{ml}$ required for an in vitro effect. A plausible explanation of this disparity would be that, since total collagen turnover is very slow, a prolonged exposure of collagen to smaller concentrations of D-penicillamine or homocysteine as in the patient may produce a more cumulative effect than that which can be reproduced in the relatively acute experimental conditions in vitro. This possibility is further supported by our preliminary observation that the solubility of collagen of experimental rats that had been administered homocysteine in their diet for several weeks is significantly increased despite the fact that the plasma homocysteine level achieved in these animals is lower than that commonly observed in human patients (Kang, A. H. unpublished data).

It should be noted that the apparently decreased amount of measurable $\epsilon$-hydroxynorleucine after direct sodium borohydride reduction of native collagenous tissues does not necessarily indicate a true diminution in the content of allysine per se but that it may be a result of binding of the aldehydic group by other compounds. Thus, analysis for $\epsilon$-hydroxynorleucine after sodium 
borohydride reduction of dermal collagenous tissue from human patients and the laboratory animals such as chicks that had been administered D-penicillamine shows low content of the compound (Kang, A. H. unpublished data). However, the measurable content of $\epsilon$-hydroxynorleucine is high if collagen present in such tissues is first extracted and purified since the D-penicillamine binding to collagen is reversible and it is removed during the purification procedure (9-11). Unfortunately, due to the limited amount of patient material available it was not possible for us to analyze for the allysine content of homocystinuric collagen after extraction and purification. However, the diminution of measurable $\epsilon$-hydroxynorleucine in the patient samples reduced directly with borohydride as compared with the controls (Table IV) does suggest an interaction between the aldehyde and homocysteine in vivo. Considerations of chemical structures of the known collagen lysyl oxidase inhibitors, such as $\beta$-aminopropionitrile on the one hand and the aminothiol lathyrogens that act via direct interaction with collagen aldehyde such as D-penicillamine on the other hand would also support such a mechanism of action by homocysteine.

The solubility of collagen of homocystinurics in nondenaturing solvents obtained in the present study is increased as compared to controls. Harris and Sjoerdsma (6) previously reported also increased solubility of collagen and increased $\alpha: \beta$ ratio in solubilized collagen, implying a defect in the "intra"-molecular cross-link or the aldol cross-link formation. However, it was previously shown that in the native type fibrils such as in vivo tissues, the aldol cross-link exists only as a part of an intermolecular cross-link, the post-histidine compound (recently shown to be histidino-hydroxymerodesmosine) and not as a separatae entity $(11,16,23,24)$. In this sense, the "intra"-molecular cross-link is only a result of extraction and solubilization of collagen and reflects the intermolecular cross-link, histidino-hydroxymerodesmosine of which it is a structural component. Thus, the diminished $\beta$-content (or the aldol condensate) in the solubilized, homocystinuric collagen is consistent with the diminished content of histidino-hydroxymerodesmosine in the native-type tissue observed in the present investigation (Table IV).

Although the precise relationship between the solubility of collagen in non-denaturing solvents and the Schiff base type of cross-links has not been clearly established, there is a reasonable amount of evidence that implicates cross-linking as one of the factors in influencing the collagen solubility. This includes the increased solubility in lathyrism viś-à-viś the deficient cross-linking as recently reviewed by Bornstein (34), the increased solubility observed in experimental animals as well as humans after D-penicillamine administration

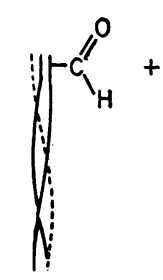

NORMAL HOMOCYSTEINE
COLLAGEN<smiles>NC(CCS)C(=O)O</smiles><smiles></smiles>

COLLAGENHOMOCYSTEINE COMPLEX
Figure 3 A mechanism proposed for the mode by which homocysteine acts to interfere with collagen cross-linking.

with defective cross-linking $(9,10,37)$, and the in vitro studies of Tanzer (38) relating the cross-linking and the solubility.

The relatively easy removal of homocysteine from collagen upon dialysis (Fig. 2) implies that the interacting forces are not strong. At the present time, the precise chemical nature of this interaction is not known. By analogy with the mechanism proposed for D-penicillamine, a possible mechanism is postulated in Fig. 3. It is known that compounds with suitably proximate thiol and amino groups will readily form a complex with aldehydes (39). Various cations, $\mathrm{pH}$ and the nature of the media as well as the nature of the ring substituents will shift the equilibrium of the reaction (40). Under appropriate conditions, the ring structure postulated for this interaction can dissociate to regenerate normal collagen with reactive aldehydes and the amino acid.

The reversibility of the homocysteine effect on the collagen molecule in the in vitro experiments also suggests that such might be the case as well in vivo. If the patients could be maintained at a very low or negligible level of homocysteinemia by therapeutic means such as with vitamin $B_{B}$ and dietary therapy, one would expect the severity of the collagen defect to diminish. A longitudinal study involving newly diagnosed vitamin $B_{8}$ responsive patients before and after therapy would be highly informative.

\section{ACKNOWLEDGMENTS}

The authors are grateful to Dr. J. Gross for his support during the investigation, and to Miss Karen Lawley, Mrs. Joanne Hazard, and Mrs. Margaret Cirtain for expert technical assistance. This work was supported by grants from the U. S. Public Health Service (AM 3564, AM 16506) and a Medical Investigatorship of the Veterans Administration. Hydroxylysinohydroxynorleucine was a generous gift of Dr. Gerald Mechanic.

\section{REFERENCES}

1. McKusick, V. A. 1966. Homocystinuria. In Heritable Disorders of Connective Tissue. C. V. Mosby Company, Saint Louis, Mo. 3rd edition. 150. 
2. Mudd, S. H., J. D. Finkelstein, J. D., F. Irreverre, and L. Laster. 1964. Homocystinuria: an enzymatic defect. Science (Wash. D. C.). $143: 1443$.

3. Ponseti, I. V., and R. S. Shepard. 1954. Lesions of the skeleton and of other mesodermal tissues in rats fed sweet-pea (Lathyrus odoratus) seeds. J. Bone Jt. Surg. 36A: 1031.

4. Levene, C. I., and J. Gross. 1959. Alterations in state of molecular aggregation of collagen induced in chick embryos by $\beta$-aminopropionitrile (lathyrus factor). $J$. Exp. Med. 110: 771.

5. Gross, J. 1963. An intermolecular defect of collagen in experimental lathyrism. Biochim. Biophys. Acta. 71: 250.

6. Harris, E. D., and A. Sjoerdsma. 1966. Collagen profile in various clinical conditions. Lancet. 2: 707.

7. Bornstein, P. 1969. Disorders of connective tissues. In Disease of Metabolism. G. G. Duncan, editor. W. B. Saunders Co., Philadelphia, $\mathrm{Pa}$. 6th edition. 654.

8. Grant, M. E., and D. J. Prockop. 1972. The biosynthesis of collagen. N. Engl. J. Med. 286: 194.

9. Nimni, M. E. 1968. A defect in the intramolecular and intermolecular cross-linking of collagen caused by penicillamine. I. Metabolic and function abnormalities in soft tissues. J. Biol. Chem. 243: 1457.

10. Deshmukh, K., and M. E. Nimni. 1969. A defect in the intramolecular and intermolecular cross-linking of collagen caused by penicillamine II. Functional groups involved in the interaction process. J. Biol. Chem. 244: 1787.

11. Kang, A. H., and J. Gross. 1970. Relationship between the intra- and intermolecular cross-links of collagen. Proc. Natl. Acad. Sci. U. S. A. 67: 1307.

12. Bailey, A. J., and C. M. Peach. 1968. Isolation and structural identification of a labile intermolecular crosslink in collagen. Biochem. Biophys. Res. Commun. 33: 812.

13. Bailey, A. J., C. M. Peach, and L. J. Fowler. 1970. Chemistry of the collagen cross-links: Isolation and characterization of two intermediate intermolecular cross-links in collagen. Biochem. J. 117: 819.

14. Tanzer, M. L., and G. Mechanic. 1968. Collagen reduction by sodium borohydride. Effects of reconstitution, maturation and lathyrism. Biochem. Biophys. Res. Commun. 32 : 885.

15. Tanzer, M. L., and G. Mechanic. 1970. Isolation of lysinonorleucine from collagen. Biochem. Biophys. Res. Commun. 39: 183.

16. Kang, A. H., B. Faris, and C. Franzblau. 1970. The in vitro formation of intermolecular cross-links in chick skin collagen. Biochem. Biophys. Res. Commun. 39: 175.

17. Bornstein, P., A. H. Kang, and K. A. Piez. 1966. The nature and location on intramolecular cross-links in collagen. Proc. Natl. Acad. Sci. U. S. A. 55: 417.

18. Bornstein, P., and K. A. Piez. 1966. The nature of the intramolecular cross-links in collagen: the separation and characterization of peptides from the cross-link region of rat skin collagen. Biochemistry. 5: 3460 .

19. Rojkind, M., L. Rhi, and M. Aguirre. 1968. Biosynthesis of the intramolecular cross-links in rat skin collagen. J. Biol. Chem. 243 : 2266.

20. Rojkind, M., A. M. Gutirrez, M. Zeichner, and R. W. Lent. 1969. The nature of the intramolecular cross-link in collagen. Biochem. Biophys. Res. Commun. 36: 350.
21. Kang, A. H., K. A. Piez, and J. Gross. 1969. Characterization of the $\alpha$-chains of chick skin collagen and the nature of the $\mathrm{NH}_{2}$-terminal cross-link region. Biochemistry. $8: 3648$.

22. Franzblau, C., A. H. Kang, and B. Faris. 1970. In vitro formation of intermolecular crosslinks in chick skin collagen. II. Kinetics. Biochem. Biophys. Res. Commun. 40: 437.

23. Tanzer, M. L., T. Houseley, L. Berube, R. Fairweather, C. Franzblau, and P. M. Gallop. 1973. Structure of two histidine-containing cross-links from collagen. $J$. Biol. Chem. 248: 393.

24. Fairweather, R. B., M. L. Tanzer, and P. M. Gallop. 1972. Aldolhistidine, a new trifunctiontial collagen crosslink. Biochem. Biophys. Res. Commun. 48: 1311.

25. Mechanic, G., and M. L. Tanzer. 1970. Biochemistry of collagen crosslinking. Isolation of a new cross-link hydroxylysinohydroxynorleucine, and its reduced precursor, dihydroxynorleucine, from bovine tendon. Biochem. Biophys. Res. Commun. 41 : 1597.

26. Gross, J., and D. Kirk. 1958. The heat precipitation of collagen from neutral salt solutions: some rate-regulating factors. J. Biol. Chem. $233: 355$.

27. Duerre, J. A., and C. H. Miller. 1966. Preparation of L-homocysteine from L-homocysteine thiolactone. Anal. Biochem. 17: 310 .

28. Gallop, P. M., O. O. Blumenfeld, E. Henson, and A. L. Schneider. 1968. Isolation and identification of $\alpha$-amino aldehydes in collagen. Biochemistry. 7: 2409.

29. Prockop, D. J., and S. Udenfriend. 1960. A specific method for the analysis of hydroxyproline in tissues and urine. Anal. Biochem. 1: 228.

30. Hamilton, P. B. 1963. Ion exchange chromatography of amino acids. Anal. Chem. $35: 2055$

31. Burn, J. A., C. F. Curtis, and H. Kaeser. 1965. A method for the production of a desired buffer gradient and its use for the chromatographic separation of arginosuccinate. J. Chromatogr. 20:310.

32. Gross, J. 1958. Studies on the formation of collagen. III. Time-dependent solubility changes of collagen in vitro. J. Exp. Med. 108: 215.

33. Piez, K. A. 1968. Cross-linking of collagen and elastin. Annu. Rev. Biochem. 37 : 547.

34. Bornstein, P. 1970. The cross-linking of collagen and elastin and its inhibition in osteolathyrism. Am. J. Med. 49: 429.

35. Gallop, P., O. O. Blumfeld, and S. Seifter. 1972. Structure and metabolism of connective tissue proteins. Annu. Rev. Biochem. 41 : 617.

36. Franzblau, C., B. Faris, R. W. Lent, L. L. Salcedo, B. Smith, R. Jaffe, and G. Crombie. 1970. Chemistry and biosynthesis of crosslinks in elastin. In Chemistry and Molecular Biology of the Intercellular Matrix. E. A. Balazs, editor. Academic Press, Inc., New York. 1:617.

37. Harris, E. D., Jr., and A. Sjoerdsma. 1966. Effect of penicillamine on human collagen and its possible application to treatment of scleroderma. Lancet. 2: 996.

38. Tanzer, M. L. 1968. Intermolecular cross-links in reconstituted collagen fibrils. J. Biol. Chem. 243: 4045.

39. Schubert, M. P. 1936. Compounds of thiol acids with aldehydes. J. Biol. Chem. 114: 341.

40. Cook, A. H., and I. M. Heilbron. 1949. H. T. Clark, J. R. Johnson, and R. Robinson, editors. Princeton University Press, Princeton, N. J. 92. 